\title{
Article \\ PLGA/PEG Nanoparticles Loaded with Cyclodextrin-Peganum harmala Alkaloid Complex and Ascorbic Acid with Promising Antimicrobial Activities
}

\author{
Sherif Ashraf Fahmy ${ }^{1,+}{ }^{+}$, Noha Khalil Mahdy ${ }^{1,+}$, Hadeer Al Mulla ${ }^{1}$, Aliaa Nabil ElMeshad ${ }^{2,3}$ (D), \\ Marwa Y. Issa ${ }^{4}$ (D) and Hassan Mohamed El-Said Azzazy ${ }^{1, *(D)}$
}

check for updates

Citation: Fahmy, S.A.; Mahdy, N.K.; Al Mulla, H.; ElMeshad, A.N.; Issa, M.Y.; Azzazy, H.M.E.-S. PLGA/PEG Nanoparticles Loaded with Cyclodextrin-Peganum harmala Alkaloid Complex and Ascorbic Acid with Promising Antimicrobial Activities. Pharmaceutics 2022, 14, 142. https://doi.org/10.3390/

pharmaceutics14010142

Academic Editors: Marcel Popa, Anca Niculina Cadinoiu and Clive Prestidge

Received: 22 November 2021

Accepted: 5 January 2022

Published: 7 January 2022

Publisher's Note: MDPI stays neutral with regard to jurisdictional claims in published maps and institutional affiliations.

Copyright: (C) 2022 by the authors. Licensee MDPI, Basel, Switzerland. This article is an open access article distributed under the terms and conditions of the Creative Commons Attribution (CC BY) license (https:// creativecommons.org/licenses/by/ $4.0 /)$
1 Department of Chemistry, School of Sciences \& Engineering, The American University in Cairo, AUC Avenue, P.O. Box 74, New Cairo 11835, Egypt; sheriffahmy@aucegypt.edu (S.A.F.); noha.khalil@aucegypt.edu (N.K.M.); hadeer.almulla@aucegypt.edu (H.A.M.)

2 Department of Pharmaceutics and Industrial Pharmacy, Faculty of Pharmacy, Cairo University, Kasr El-Aini Street, Cairo 11562, Egypt; aliaa.elmeshad@pharma.cu.edu.eg

3 Department of Pharmaceutics, Faculty of Pharmacy and Drug Technology, The Egyptian Chinese University, Gesr El Suez Street, Cairo 11786, Egypt

4 Department of Pharmacognosy, Faculty of Pharmacy, Cairo University, Kasr El-Aini Street, Cairo 11562, Egypt; marwa.issa@pharma.cu.edu.eg

* Correspondence: hazzazy@aucegypt.edu; Tel.: +20-226-152-559; Fax: +20-227-957-565

+ These authors contributed equally to this work.

\begin{abstract}
Antimicrobial drugs face numerous challenges, including drug resistance, systemic toxic effects, and poor bioavailability. To date, treatment choices are limited, which warrants the search for novel potent antivirals, including those extracted from natural products. The seeds of Peganum harmala L. (Zygophyllaceae family) have been reported to have antimicrobial, antifungal, and anticancer activities. In the present study, a 2-hydroxy propyl- $\beta$-cyclodextrin $(\mathrm{HP} \beta C D) /$ harmala alkaloid-rich fraction (HARF) host-guest complex was prepared using a thin-film hydration method to improve the water solubility and bioavailability of HARF. The designed complex was then co-encapsulated with ascorbic acid into PLGA nanoparticles coated with polyethylene glycol (HARF-HPBCD/AA@PLGAPEG NPs) using the $\mathrm{W} / \mathrm{O} / \mathrm{W}$ multiple emulsion-solvent evaporation method. The average particle size, PDI, and zeta potential were $207.90 \pm 2.60 \mathrm{~nm}, 0.17 \pm 0.01$, and $31.6 \pm 0.20 \mathrm{mV}$, respectively. The entrapment efficiency for HARF was $81.60 \pm 1.20 \%$ and for ascorbic acid was $88 \pm 2.20 \%$. HARFHPßCD/AA@PLGA-PEG NPs had the highest antibacterial activity against Staphylococcus aureus and Escherichia coli (MIC of $0.025 \mathrm{mg} / \mathrm{mL}$ ). They also exhibited high selective antiviral activity against the H1N1 influenza virus (IC50 $2.7 \mu \mathrm{g} / \mathrm{mL}$ ) without affecting the host (MDCK cells). In conclusion, the co-encapsulation of HPCD-HARF complex and ascorbic acid into PLGA-PEG nanoparticles significantly increased the selective H1N1 killing activity with minimum host toxic effects.
\end{abstract}

Keywords: Peganum harmala; ascorbic acid (Vitamin C); 2-hydroxy propyl- $\beta$-cyclodextrin; PLGA; PEG; antiviral; antibacterial

\section{Introduction}

Microbial infections, including bacterial and viral infections, represent a significant health burden responsible for many deaths worldwide. Influenza A virus causes the hospitalization of about 4 million cases and the death of 600,000 patients each year. The pervasive use of antimicrobials is the leading cause of resistance to the existing medications [1]. Moreover, most antimicrobial agents suffer from many drawbacks, including systemic adverse reactions, allergy, poor bioavailability, and narrow spectrum [2,3].

Nature provides an enormous library of novel chemicals that can be explored to develop antimicrobials. Peganum harmala L. (Zygophyllaceae family) is a member of the Zygophyllaceae family native to the area from the eastern Mediterranean region to India [3,4]. 
The seeds of $P$. harmala are rich in harmala alkaloids such as quinazoline and $\beta$-carboline alkaloids. The major alkaloid, harmine, is responsible for the various pharmacological activities of the harmala seeds [5-7]. Several studies have reported the promising antimicrobial activities of $P$. harmala extracts $[8,9]$.

Ascorbic acid is an essential dietary nutrient required for various biological functions [10]. Several in vivo studies have reported the ability of ascorbic acid to prevent and alleviate many types of viral infections [10,11]. Ascorbic acid was found to improve the immune response to viral infections by stimulating the function and proliferation of T-lymphocyte and NK-lymphocyte and the production of interferon [11].

Despite the global trend to replace synthetic antimicrobials with natural ones, the use of natural products to treat microbial infections may face challenges similar to those of synthetic drugs, such as poor water solubility, low bioavailability, and non-selective targeting the infected organ. Thus, numerous nanoplatforms, including liposomes, supramolecular systems, and polymeric nanoparticles, were designed, being reported to remarkably ameliorate the therapeutic activities of different types of biologically active compounds [12-18].

Supramolecular host molecules, such as cyclodextrins (CDs), are involved in overcoming the poor water solubility of the natural compounds via the formation of host-guest complexes. CDs are amphiphilic cyclic oligosaccharides obtained from the enzymatic hydrolysis of starch. They comprise three types, namely, $\alpha, \beta$, and $\gamma$-CDs, consisting of six, seven, and eight glucopyranose units, respectively [19]. In this context, 2-hydroxy propyl $\&$ cyclodextrin (HPBCD) is a promising derivative of CDs due to its safety, high water solubility, and ability to selectively form inclusion complexes with various drug molecules [20].

Polymeric nanoparticles (NPs) have been extensively involved in drug delivery, owing to their ability to encapsulate different therapeutically active compounds into their matrix and the ability of their surfaces to be decorated with different functional groups [3,21,22]. Consequently, this could improve the stability of their cargos and prolong their half-lives. Poly (lactic-co-glycolic acid) (PLGA) is commonly employed in the fabrication of polymeric NPs since it is a biocompatible and biodegradable polymer with favorable physicochemical properties $[3,21,22]$. The surface decoration of PLGA NPs with polyethylene glycol (PEG) has been reported to have many advantages, such as (i) improving the water solubility of the PLGA NPs and their hydrophobic cargos, (ii) increasing the surface charge and the steric hindrance on the PLGA NPs thus extending the stability of the NPs and minimizing their aggregation, (iii) causing a stealth effect that prolongs the systemic circulation duration of drugs via inhibiting the opsonization effect, and (iv) enhancing the release of the drugs out of the polymeric matrix [23,24]. Many studies have reported using PEGylated PLGA NPs as promising nanocarriers for various natural bioactive compounds, biotherapeutics (as peptides, proteins, or vaccines), and synthetic drugs [23-27].

In the present study, a 2-hydroxy propyl- $\beta$ - cyclodextrin (HP $\beta C D$ )/harmala alkaloidrich fraction (HARF) host-guest complex was fabricated using the thin-film hydration method to alleviate the water solubility of HARF. The complex formation was investigated by ${ }^{1} \mathrm{H}$ NMR spectroscopy and phase solubility study. The prepared complex was then coencapsulated with ascorbic acid into PEGylated PLGA (HARF-HPßCD/AA@PLGA-PEG $\mathrm{NPs}$ ) utilizing the $\mathrm{W} / \mathrm{O} / \mathrm{W}$ multiple emulsion-solvent evaporation method. The designed NPs were physically characterized in terms of average size, surface charge, polydispersity index (PDI), entrapment efficiency, and morphology. Additionally, the release of HARFHP $\beta C D$ complex and ascorbic acid (AA) from HARF-HPßCD/AA@PLGA-PEG NPs was studied, and the release profile was acquired. Finally, the antibacterial and antiviral activities of HARF-HPßCD/AA@PLGA-PEG NPs were evaluated.

\section{Materials and Methods}

\subsection{Materials}

2-Hydroxy propyl $\mathrm{B}$ cyclodextrin was purchased from BLD Pharmatech Co., Limited (Cincinnati, OH, USA). Poly (D,L-lactide-co-glycolide) (PLGA) and polyethylene glycol 
6000 (PEG) were obtained from Sigma-Aldrich (St. Louis, MO, USA). Polyvinyl alcohol (PVA; 98\% hydrolyzed, MW $\approx 13,000$ ) was obtained from Acros Organics (Geel, Belgium). Dimethylsulfoxide was purchased from Fisher Chemicals (Fair Lawn, NJ, USA). Tween 80 was purchased from El-Nasr Pharmaceutical Chemicals Co. (Cairo, Egypt). Tryptic soy agar was purchased from Millipore (Bedford, MA, USA). Phosphate-buffered saline, streptomycin, penicillin, fetal bovine serum, trichloroacetic acid, Dulbecco's modified Eagle's medium (DMEM), SRB, and tris (hydroxymethyl)aminomethane were purchased from Lonza (Basel, Switzerland).

\subsection{Extraction and Isolation of Major P. harmala Alkaloids}

Dried mature seeds of P. harmala L. were purchased from the local Egyptian market. The major alkaloids of $P$. harmala seeds were extracted, isolated, and characterized according to our previously reported method $[5,6]$.

\subsection{Preparation of Harmala Alkaloid-Rich Fraction/2-Hydroxy Propyl $\beta$ Cyclodextrin Complex (HARF-HPßCD)}

HARF-HPßCD inclusion complex was designed via the thin-film hydration method, as described elsewhere, with some modifications [28]. Briefly, a thin film was formed by dissolving HARF in methanol followed by drying in a round bottom flask using a rotary evaporator. Separately, $5 \%(w / v)$ of HPßCD solution was prepared and subsequently added to the film, followed by $30 \mathrm{~min}$ sonication in a SONOREX DIGITAL $10 \mathrm{P}$ sonicator (BANDELIN electronic GmbH \& Co. KG, Darmstadt, Germany). Afterward, the complex solution was stirred for another $30 \mathrm{~min}$ and purified through filtration using a $0.22 \mu \mathrm{m}$ nylon filter. The filtrate was then dried in a lyophilizer (TOPTION TOPT-10C Freeze dryer, Toption Group Co., Xi'an, China).

\subsection{1. ${ }^{1} \mathrm{H}$ NMR Spectroscopy of HARF-HPßCD Complex}

${ }^{1} \mathrm{H}$ NMR spectra of HPßCD and the inclusion complex were measured on a $400 \mathrm{MHz}$ FT-NMR spectrometer (ECA-500, JEOL, Tokyo, Japan) in $\mathrm{D}_{2} \mathrm{O}$ solutions. The scanning range of the hydrogen spectrum is $1-13 \mathrm{ppm}$.

\subsubsection{Phase Solubility Study}

The phase solubility study was performed, as described elsewhere with some modifications [29], to confirm the formation of the HARF-HPßCD inclusion complex using UV spectroscopy (FLUOstar Omega microplate reader, BMG Labtech, Offenburg, Germany) at $\lambda=373 \mathrm{~nm}$ [30]. Briefly, an excess amount of HARF was added to $5 \mathrm{~mL}$ of several mixtures containing successively increasing concentrations of HPßCD (ranging from 0 to $200 \mathrm{~mm}$ ) all in deionized water. These mixtures were then sealed and stirred at room temperature until equilibrium had been reached. The mixtures were then centrifuged at $4000 \mathrm{rpm}$ for 10 min (Hermle Z326K, Wehingen, Germany), and the absorbance was measured at $373 \mathrm{~nm}$ using UV spectrophotometer.

The stability constant $\left(K_{1: 1}\right)$ was estimated utilizing the slope of the linear correlation and the intrinsic solubility $\left(S_{0}\right)$ using Equation (1) [31,32].

$$
K_{1: 1}=\frac{\text { Slope }}{S_{0}(1-\text { Slope })}
$$

Then, the complexation efficiency $(C E)$ was computed employing the intrinsic solubility and the stability constant using Equation (2) [31,32].

$$
C E=S_{0} * K_{1: 1}
$$

where $S_{0}$ is the intrinsic solubility, and $K_{1: 1}$ is the stability constant. 
2.4. Preparation of PEG-Coated PLGA Nanoparticles Dual-Loaded with Ascorbic Acid (AA) and HARF-HPßCD Inclusion Complex (HARF-HPßCD/AA@PLGA-PEG NPS)

The designed HARF-HPßCD complex was co-loaded with AA into PLGA NPs coated with PEG (HARF-HPßCD/AA@PLGA-PEG NPs) using the W/O/W multiple emulsionsolvent evaporation method, as previously reported with some modifications [3,7,33,34].

Briefly, $300 \mathrm{mg}$ of PLGA and $100 \mathrm{mg}$ PEG 6000 were dissolved in $8 \mathrm{~mL}$ dichloromethane (DCM), forming the emulsion's organic phase (O). Then, HARF-HPßCD complex and AA were dissolved in water (the $W / W$ ratio of each drug/PLGA was 0.2:1) to obtain the inner aqueous phase (W1). Into the previously prepared organic phase, we emulsified $800 \mu \mathrm{L}$ of the internal aqueous phase using a homogenizer at 11,000 rpm for $8 \mathrm{~min}$ in an ice bath to form a W1/O emulsion (first emulsion). Then, $2.5 \%$ polyvinyl alcohol was dissolved in $100 \mathrm{~mL}$ deionized water to form the external aqueous phase (W2). The first emulsion was added to the external aqueous phase (W2) and emulsified by homogenization at 11,000 rpm for $8 \mathrm{~min}$ in an ice bath. The resulting W1/O/W2 emulsion (second emulsion) was stirred overnight using a magnetic stirrer to allow solvent evaporation and particle hardening. Afterward, the nanoparticle colloid was lyophilized (TOPTION TOPT-10C Freeze dryer, Toption Group Co., Limited).

\subsection{Characterization of the Designed HARF-HPßCD/AA@PLGA-PEG NPS}

The average particle size and polydispersity index (PDI) were determined using a Zetasizer Nano ZS equipped with a $10 \mathrm{~mW}$ HeNe laser, allowing for measurements at 633 $\mathrm{nm}$ and a detection angle of $173^{\circ}$ backscatter (Malvern Instruments, Worcestershire, UK). The $\zeta$-potential was measured using laser Doppler velocimetry [35-37].

The morphological features of the prepared nanoparticles were investigated using scanning electron microscopy (SEM) via high-resolution field emission scanning electron microscopy (FESEM) (LEO SUPRA 55, Carl Zeiss, Oberkochen, Germany) with an acceleration voltage of $1.00 \mathrm{kV}$. Before conducting the SEM study, we coated freeze-dried PLGA NPs via gold sputtering (current: $10 \mathrm{~mA}$ ) for 2 min under a nitrogen atmosphere. The measurements were performed using the image processing program Image $(\mathrm{NIH}$, Bethesda, MD, USA).

\subsection{Entrapment Efficiency}

The entrapment efficiency (EE) of HARF-HPBCD/AA@PLGA-PEG NPs was measured indirectly by centrifugation $\left(15,000 \mathrm{rpm}, 1 \mathrm{~h}, 4^{\circ} \mathrm{C}\right)$, followed by ultrafiltration of the supernatant. The quantities of the HARF and AA unencapsulated in the ultrafiltrate were determined by a FLUOstar Omega microplate reader (BMG Labtech, Offenburg, Germany) spectrophotometer at 373 and $287 \mathrm{~nm}$, respectively, using Equation (3) [37-39].

$$
E E(\%)=\frac{\text { Initial feeded drug }- \text { Final loaded drug }}{\text { Initial feeded drug }} \times 100
$$

\subsection{In Vitro Release Study of HARF-HPßCD Complex and Ascorbic Acid from HARF-HPßCD/AA@PLGA-PEG NPS}

The cumulative release \% of HARF and AA from HARF-HPßCD/AA@PLGA-PEG NPs was investigated utilizing the dialysis membrane method. Briefly, $1 \mathrm{~mL}$ of the NPs was loaded to a dialysis bag (cutoff molecular weight of 12,000-14,000 Da). The dialysis bag was inserted into $50 \mathrm{~mL}$ of PBS at pH 7.4 with $2 \%$ Tween in a proper jar. The whole system was left on a stirrer at $37^{\circ} \mathrm{C}$. A $1 \mathrm{~mL}$ aliquot of the sample was withdrawn for analysis and immediately replaced with another equal volume of warmed buffer at specific time intervals. The concentrations of HARF and AA were determined by a FLUOstar Omega microplate reader (BMG Labtech, Offenburg, Germany) spectrophotometer at 373 and $287 \mathrm{~nm}$ wavelengths, respectively. 
The cumulative release (\%) was calculated according to Equation (4) [40].

$$
\text { Cumulative release }(\%)=\frac{\mathrm{Vs}_{1}^{n-1} c(n-1)+V_{o} C n}{\mathrm{mo}} \times 100
$$

where Vs is the volume of each sample removed, $c(n-1)$ is the bulk concentration before sampling, $C n$ is the concentration of the sample, $V o$ is the bulk volume of the release medium, and mo is the original amount of the drug in the nanoparticles tested.

\subsection{Antibacterial Assay for the Designed HARF-HPßCD/AA@PLGA-PEG NPS}

\subsubsection{Preparation of the Inoculum Using Colony Suspension Approach}

Staphylococcus aureus ATCC ${ }^{\circledR} 6538$ (lot no. 4600502) and Escherichia coli ATCC ${ }^{\circledR} 8739$ (lot no. 380063) were obtained from American Type Culture Collection (Manassas, VA, USA). Tryptic soy broth $(100 \mathrm{~mL})$ was used as inoculation medium for either the Gram-positive or Gram-negative bacteria, then incubated at $37.0 \pm 1.0^{\circ} \mathrm{C}$ for $24 \pm 2 \mathrm{~h}$. A loopful of the broth was streaked onto tryptic soy agar medium and incubated at $37.0{ }^{\circ} \mathrm{C}$ for $21 \pm 3 \mathrm{~h}$. Three or four colonies (from each plate) were inoculated in broth, and the suspension was incubated till turbidity reached 0.5 McFarland standard. The inoculum density was standardized utilizing a $0.5 \mathrm{McFarland}$ standard and DensiCHEK ${ }^{\odot}$ optical device (BioMérieux, Marcy l'Etoile, France). The obtained suspensions contained about $1.0 \times 10^{8} \mathrm{CFU} / \mathrm{mL}$ of Staphylococcus aureus or Escherichia coli.

\subsubsection{Broth Macrodilution Method}

The antibacterial activities of plain PLGA-PEG NPs, HARF, and HARF-HPBCD/ AA@PLGA-PEG NPs were evaluated by adding and mixing $5.0 \mathrm{~mL}$ from each sample to $5.0 \mathrm{~mL}$ broth (1:2 dilution) according to a previously reported method [41]. Next, $5.0 \mathrm{~mL}$ of the 1:2 dilution was pipetted using a new tip and mixed with $5.0 \mathrm{~mL}$ broth (1:4). Ten dilutions for each bacterial strain were prepared and inoculated in a 24 -well plate. Then, $100 \mu \mathrm{L}$ of prepared inoculum was added to each well, resulting in a final concentration of $5.0 \times 10^{5} \mathrm{CFU} / \mathrm{mL}$. An additional $100 \mu \mathrm{L}$ from each bacterial strain suspension was diluted and cultured to confirm the inoculum density. All plates were incubated at $37.0^{\circ} \mathrm{C}$ for $24 \mathrm{~h}$ and then kept in the dark to monitor growth. All control wells yielded a turbid solution. The inoculum density was $4-6 \times 10^{5} \mathrm{CFU} / \mathrm{mL}$ for both evaluated bacterial strains, with reference to the Clinical and Laboratory Standards Institute (CLSI) procedures (document M07, A09) [41].

\subsection{Cytotoxicity and Antiviral Assays}

The human influenza H1N1 and Madin-Darby Canine Kidney (MDCK) cells were obtained from American Type Culture Collection (University Boulevard, Manassas, VA, USA). Vero E6 cells were grown in DMEM medium supplemented with $10 \%$ fetal bovine serum and $0.1 \%$ antibiotic/antimycotic solution. Gibco BRL provided the antibiotic and antimycotic solution, trypsin-EDTA, fetal bovine serum, and DMEM medium (Grand Island, NY, USA).

Cytopathic effect (CPE) reduction assay was used to evaluate the antiviral activities of plain PLGA-PEG NPs, HARF, and HARF-HPßCD/AA@PLGA-PEG NPs in cell culture systems, as described elsewhere with some modifications [42,43]. Briefly, MDCK cells seeded into a 96-well culture plate at a density of $2 \times 10^{4}$ cells per well were infected with $0.1 \mathrm{~mL}$ (CCID50) influenza (H1N1) of the diluted viral suspension of Influenza H1N1 and then incubated at $37^{\circ} \mathrm{C}$ for $60 \mathrm{~min}$ to facilitate the adsorption of the virus. The antiviral activity for each sample was determined using a twofold diluted concentration of 1-100 $\mathrm{\mu g} / \mathrm{mL}$. Culture plates were incubated at $37^{\circ} \mathrm{C}$ in $5 \% \mathrm{CO}_{2}$ for $72 \mathrm{~h}$. The development of the cytopathic effect was monitored by light microscopy. The cell monolayers were stained $(0.03 \%$ crystal violet in $2 \%$ ethanol and $10 \%$ formalin). After washing and drying, the optical density was measured at 540/630 nm. The antiviral activities were calculated according to Pauwels et al. [44], employing Equation (5). 
Antiviral activity $\%=\frac{(\text { mean optical density of cell controls }- \text { mean optical density of virus controls })}{\text { (Optical density of the test }- \text { mean optical density of virus controls })} \times 100$

The cytotoxicity was evaluated against MDCK cells before conducting the aforementioned assay. Cells were seeded at a density of $2 \times 10^{4}$ cells per well in a 96-well culture plate. After $24 \mathrm{~h}$, the culture medium containing serially diluted samples was added to the cells and incubated for $72 \mathrm{~h}$ before being removed, and the cells were washed with PBS. The next steps were carried out in the same manner as described above for the antiviral activity assay. The 50\% cytotoxic concentrations (CC50) and the 50\% inhibitory concentration (IC50) were computed using GraphPad PRISM Software (Graph-Pad Software, San Diego, CA, USA). Selectivity index (SI) was estimated as the ratio of CC50 to IC50.

\section{Results and Discussion}

\subsection{Characterization of the Prepared $H A R F-H P \beta C D$ Complex}

\subsection{1. ${ }^{1} \mathrm{H}$ NMR Spectroscopy of the HARF-HPBCD Complex}

${ }^{1} \mathrm{H}$ NMR analyses performed in $\mathrm{D}_{2} \mathrm{O}$ could shed more light on the host-guest complexation between HPßCD and other guest molecules and could provide clues on the inclusion of guest molecules into the hydrophobic cavity of the host molecule. Upon the inclusion of the guest molecule into the HPBCD cavity, an upfield shift of the H-3 and H-5 (hydrogen atoms placed in the interior cavity of HPBCD) occurred due to their shielding by the guest molecule (the chemical structure of HPBCD is presented in Figure S1A). On the other hand, H-1, H-2, H-4, and H-6 (hydrogen atoms localized on the outer surface of HPBCD) will experience milder chemical shifts. In the present work, the suggestion of the HARF-HPßCD complex foundation was grounded on modifying the ${ }^{1} \mathrm{H}$ NMR spectra of the pure HPBCD upon its complexation with HARF (Figure S1). The ${ }^{1} \mathrm{H}$ NMR chemical shifts (in ppm) of HPBCD protons in the presence and absence of HARF are presented in Table 1 . The induced chemical shift, $\delta(\mathrm{ppm})$, is the difference in chemical shifts of HPBCD protons before and after the formation of the HARF-HPBCD complex. In this context, a positive sign of $\delta(\mathrm{ppm})$ indicates a downfield shift, while a negative sign indicates an upfield one. It was shown that the H-3 and $\mathrm{H}-5$ protons experienced more remarkable HARF-induced chemical shifts than the outer surface protons (H-1, H-2, H-4, and H-6), indicating that HARF was only included within the HPßCD cavity. Furthermore, the clear upfield shift of H-3 and H-5 protons signals was due to the inclusion of $\pi$-electron-rich aromatic groups of HARF inside the host cavity. These findings agree very well with the previous studies, which reported that the upfield proton shifts of $\mathrm{H}-3$ and $\mathrm{H}-5$ indicate inclusion complexation [45-48].

Table 1. The chemical shifts (ppm) of HP $\beta C D$ before and after forming the HARF-HPßCD complex.

\begin{tabular}{ccccccc}
\hline & \multicolumn{7}{c}{ Chemical Shifts $(\boldsymbol{\delta}, \mathbf{p p m})$} \\
\cline { 2 - 7 } & $\mathbf{H - 1}$ & $\mathbf{H - 2}$ & $\mathbf{H}-\mathbf{3}$ & $\mathbf{H - 4}$ & $\mathbf{H - 5}$ & $\mathbf{H - 6}$ \\
\hline HPBCD & 4.899 & 3.310 & 3.768 & 3.329 & 3.552 & 3.696 \\
\hline HARF-HPßCD complex & 4.877 & 3.307 & 3.741 & 3.307 & 3.526 & 3.675 \\
\hline$\Delta \delta$ & -0.022 & -0.003 & -0.027 & -0.022 & -0.026 & -0.021 \\
\hline
\end{tabular}

\subsubsection{Phase Solubility Study}

The solubility of HARF was determined by plotting the change with HP $\beta C D$ concentration, as presented in Figure 1 . The $R^{2}$ value of the extrapolated curve was 0.9807 , suggesting that a remarkable linear correlation between HARF solubility and HP $\beta C D$ concentration where the solubility of HARF increased with increasing the concentration of HP $\beta C D$. As previously described by Higuchi and Connors, this phase solubility diagram displays the $\mathrm{A}_{\mathrm{L}}$-type pattern, indicating a complex stoichiometry of 1:1 (HARF/HP $\left.\beta C D\right)$ [29,31]. More- 
over, the slope was $>0.0$ and $<1.0$, while the $\mathrm{K}$ value was $>0.0$, confirming the formation of a 1:1 complex [31].

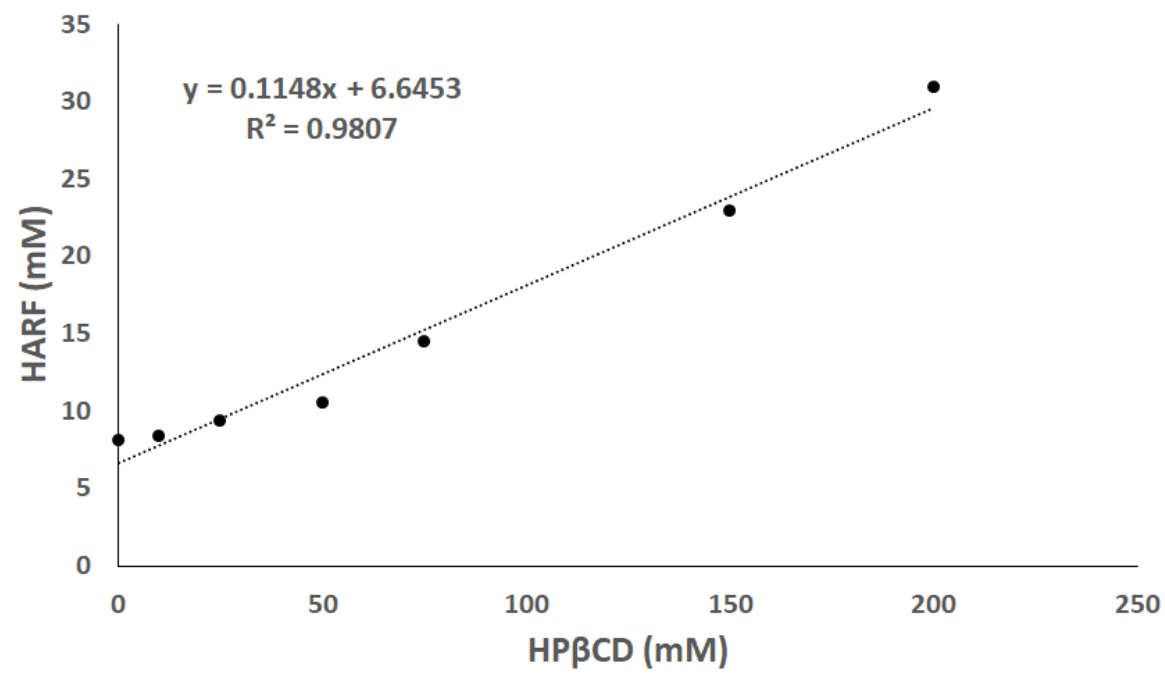

Figure 1. Phase solubility diagram of HARF in the presence of several mixtures containing successively increasing concentrations of $\mathrm{HP} \beta C D$.

The stability constant and the complexation efficiency (CE) were $81.4 \mathrm{M}^{-1}$, and 0.66 , respectively, similar to values reported previously [31,32,49]. This showed that the HP $\beta C D$ had improved the water solubility of HARF via the formation of the host-guest complex.

\subsection{Characterization of the HARF-HPßCD/AA@PLGA-PEG NPS}

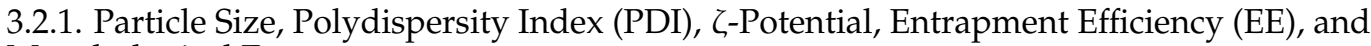
Morphological Features

The average particle size and PDI of the designed HARF-HPßCD/AA@PLGA-PEG NPs were $207 \pm 2.60 \mathrm{~nm}$ and $0.17 \pm 0.01$, respectively (Table 2). These values lie within the range of the previously reported nanoparticles that exhibited improved biomedical applications [50,51]. The particle size distribution of the nanoparticles is presented in Figure 2. The $\zeta$-potential of the designed nanoparticles showed a high negative surface charge of $-31.60 \pm 0.20 \mathrm{mV}$. This is attributed to the presence of the highly negatively charged PEG coating the PLGA NPs. Using PEG as a coat for the NPs improves the stability of the PLGA NPs in aqueous media, enabling their long shelf life. Moreover, PEG inhibits the aggregation of NPs through its steric hindrance effect [49].

Table 2. Average particle size, PDI, $\zeta$-potential, and entrapment efficiency of HARF-HPßCD/AA@PLGAPEG NPs.

\begin{tabular}{|c|c|c|c|c|c|}
\hline \multirow{2}{*}{ Formula } & \multirow{2}{*}{ Average Size (nm) } & \multirow{2}{*}{ PDI } & \multirow{2}{*}{$\zeta$-Potential $(\mathrm{mV}) \pm \mathrm{SD}$} & \multicolumn{2}{|c|}{ Encapsulation Efficiency (\%) } \\
\hline & & & & HARF & AA \\
\hline $\begin{array}{c}\text { HARF-HPßCD/AA@ } \\
\text { PLGA-PEG NPs }\end{array}$ & $207 \pm 2.60$ & $0.17 \pm 0.01$ & $-31.60 \pm 0.20$ & $81.60 \pm 1.20$ & $87 \pm 2.20$ \\
\hline
\end{tabular}

The entrapment efficiencies of the HARF and AA are presented in Table 2.

The high entrapment efficiencies of HARF and AA are attributed to the PEG coating the PLGA NPs founding a barrier that surrounds and protects the loaded drugs, preventing their loss during the homogenization step and retaining their stability [52]. The capacity to entrap high concentrations of drugs supports sustained drug release [53].

As demonstrated in Figure 3A, SEM analysis showed a spherical shape of the prepared NPs. The mean average size of the NPs was determined by utilizing the image processing program ImageJ (NIH, Bethesda, MD, USA) and was found to be $204.5 \pm 70.6 \mathrm{~nm}$ (Figure 3B, which is close to that obtained from the dynamic light scattering $(207 \pm 2.6)$. 


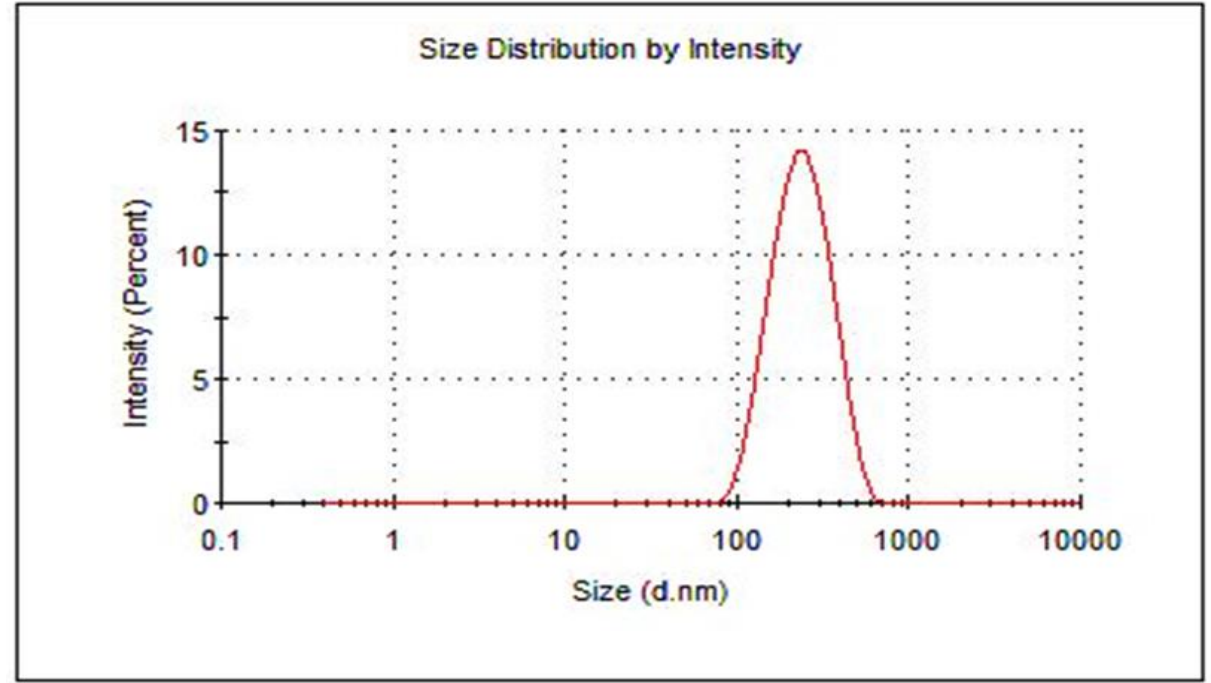

Figure 2. Particle size distribution of the prepared HARF-HPßCD/AA@PLGA-PEG NPs using DLS analysis.
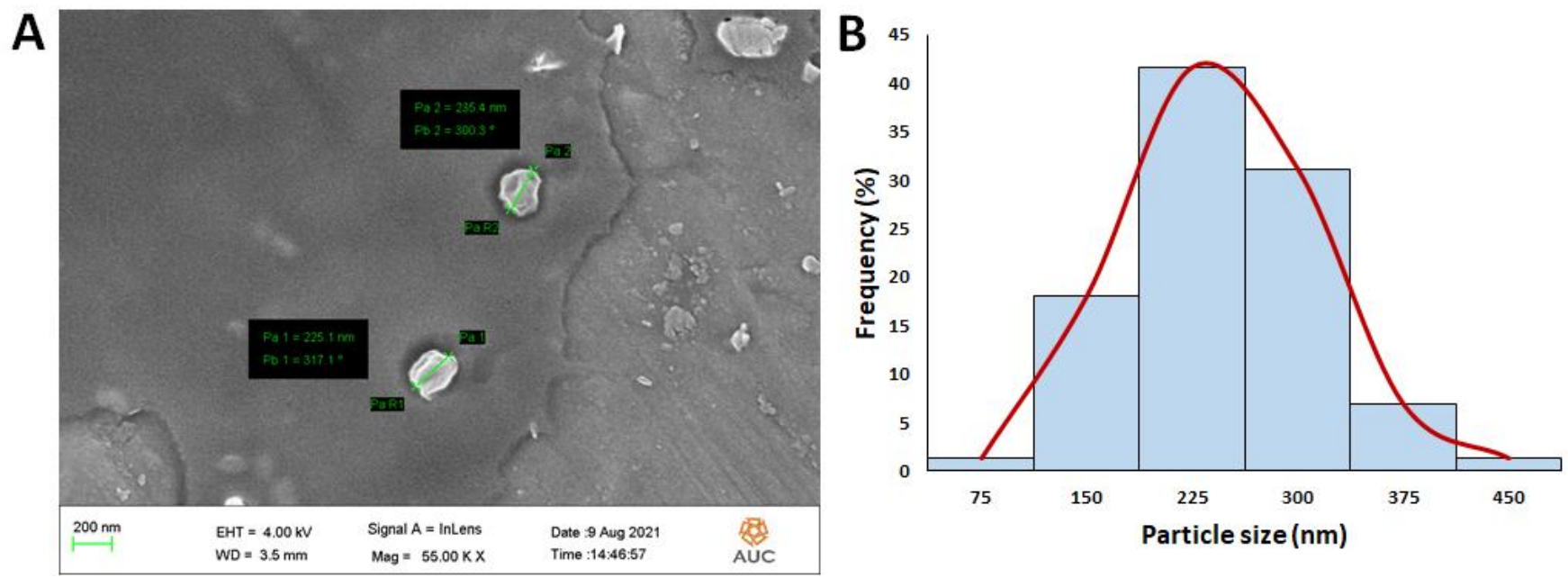

Figure 3. (A) Scanning electron microscopy (SEM) images of the HARF-HPßCD/AA@PLGA-PEG NPs. (B) Particle size (nm) histogram of the designed HARF-HPßCD/AA@PLGA-PEG NPs generated through employing the image processing program Image (NIH, Bethesda, MD, USA).

\subsubsection{In Vitro Release Study}

Figure 4 portrays the release profile of HARF-HPBCD complex and AA from the HARF-HPBCD/AA@PLGA-PEG NPs. The release profile showed an initial release of $29.8 \pm 4.9 \%$ and $66.7 \pm 6.8 \%$ for HARF-HPBCD complex and AA, respectively, in the first $2 \mathrm{~h}$, which increased to $64.6 \pm 3 \%$ and $76.6 \pm 1.3 \%$, respectively, over $48 \mathrm{~h}$. These release profiles are attributed to the hydrolytic cleavage of the ester bonds of the PLGA copolymer in the presence of water [54]. Moreover, coating NPs with PEG was reported to enhance the permeability and release of the loaded drugs [55]. The faster release rates of AA compared to HARF complex could be due to the higher molecular weight of the complex, making its diffusion out of the dialysis membrane much slower than that of AA. 


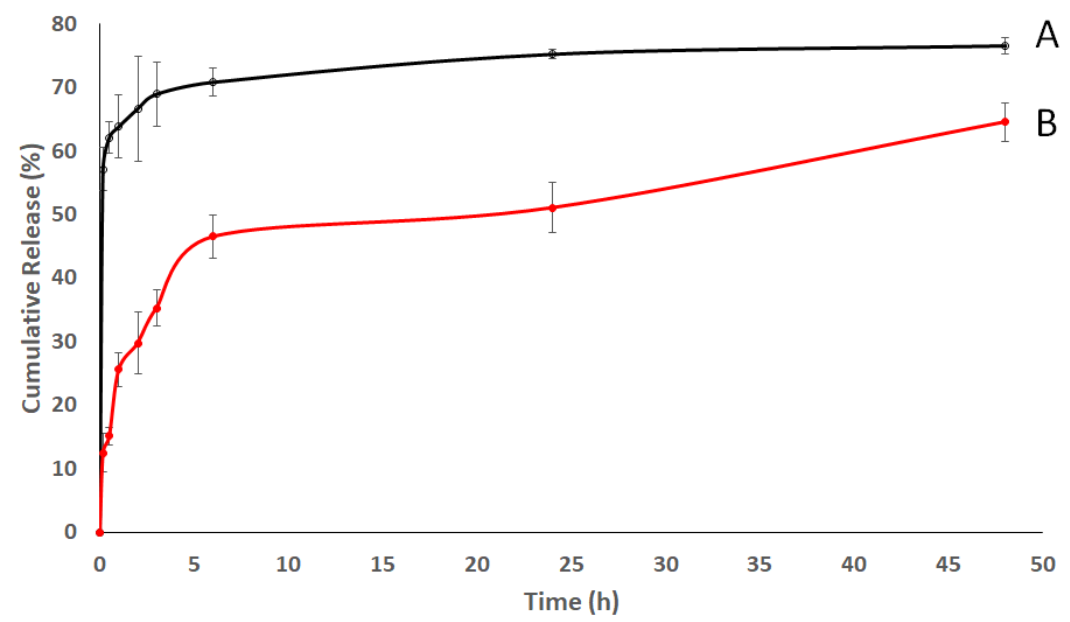

\section{$A$}

B

Figure 4. Time-dependent release profiles of (A) AA and (B) HARF-HPßCD complex from HARFHPßCD/AA@PLGA-PEG NPs at $37^{\circ} \mathrm{C}$ into phosphate-buffered saline.

\subsubsection{Antibacterial Assay for the Designed HARF-HPßCD/AA@PLGA-PEG NPs}

The bacterial activities of the HARF, plain PLGA-PEG NPs, and HARF-HPßCD/AA@ PLGA-PEG NPs were assessed against $S$. aureus and E. coli. HARF-HPBCD/AA@PLGAPEG NPs exhibited high antibacterial activity against $S$. aureus and E. coli (MIC of $0.025 \mathrm{mg} / \mathrm{mL}$ ), as compared to free HARF (MIC of $0.5 \mathrm{mg} / \mathrm{mL}$ ), as shown in Table 3 . On the other hand, PLGA-PEG NPs showed no antibacterial activities. The HARFHPßCD/AA@PLGA-PEG NPs showed higher bactericidal activity as compared to free HARF. This could possibly be attributed to the improved hydrophilicity of HARF upon its inclusion inside the HPBCD cavities. Furthermore, the NPs can adhere to the bacterial cell wall due to their effective surface areas, releasing their cargo across the cell wall [34,56-58]. The bactericidal activity of HARF is attributed to the presence of high concentrations of $\beta$-carboline and quinazoline alkaloids, which have been reported to intercalate the bacterial DNA [6].

Table 3. Bactericidal activity of HARF and HARF-HPßCD/AA@PLGA-PEG NPs against Staphylococcus aureus and Escherichia coli.

\begin{tabular}{cccc}
\hline \multirow{2}{*}{ Bacterial Strain } & \multicolumn{3}{c}{ Minimum Inhibitory Concentration (MIC in mg/mL) } \\
\cline { 2 - 4 } & PLGA-PEG NPs & HARF & HARF-HPBCD/AA@PLGA-PEG NPs \\
\hline Staphylococcus aureus & 0 & 0.5 & 0.025 \\
Escherichia coli & 0 & 0.5 & 0.025 \\
\hline
\end{tabular}

\subsubsection{Cytotoxicity and Antiviral Activity Assays}

Treatment choices for viral infections are limited and face many challenges, such as drug resistance, systemic toxic effects, and poor bioavailability. This warrants the search for effective antiviral agents that can overcome the shortcomings of their current counterparts. The antiviral activities of the HARF, PLGA-PEG NPs, and HARF-HPßCD/AA@PLGAPEG NPs against influenza A (H1N) were investigated through employing the cytopathic effect (CPE) reduction assay. The PLGA-PEG showed no antiviral activity. The developed HARF-HPCD/PLGA-PEG NPs exhibited high selective antiviral activity against the H1N1 influenza virus (Table 4) without affecting the host, MDCK cells, (IC50 of $2.7 \mu \mathrm{g} / \mathrm{mL}$; CC50 of $110.4 \mu \mathrm{g} / \mathrm{mL}$; and selective index, CC50/IC50, of 41.2) compared to free HARF (IC50 of $30.2 \mu \mathrm{g} / \mathrm{mL}$, CC50 of $238.8 \mu \mathrm{g} / \mathrm{mL}$, and selective index of 7.9). The NPs decompose, releasing their cargos that kill the virus selectively without harming the host cells. HARF is reported to exert its antiviral activity by inhibiting the viral polymerase activity and consequently viral RNA replication [59]. On the other hand, the co-encapsulation of ascorbic acid causes a synergistic antiviral effect against the influenza virus by increasing the generation of interferon (IFN)- $\alpha / \beta[60,61]$. 
Table 4. Antiviral activity of HARF and HARF-HPßCD/AA@PLGA-PEG NPs against influenza A (H1N1) virus.

\begin{tabular}{cccc}
\hline Sample & CC50 $(\mu \mathrm{g} / \mathrm{mL})$ & IC50 $(\mu \mathrm{g} / \mathrm{mL})$ & SI \\
\hline Plain PLGA-PEG & 0 & 0 & 0 \\
HARF & 238.8 & 30.2 & 7.9 \\
HARF-HPBCD/AA@PLGA-PEG NPs & 110.4 & 2.7 & 41.2 \\
\hline
\end{tabular}

\title{
4. Conclusions
}

In this work, HARF was first mixed with HPßCD as a host molecule to form an inclusion complex. This was done to improve the solubility of HARF, which is highly hydrophobic. Finally, AA and HARF-HPßCD inclusion complex were co-loaded into the PLGA-PEG nanoparticles to form the final biodegradable delivery system with enhanced release and bioavailability. The fabricated HARF-HPBCD/AA@PLGA-PEG NPs demonstrated acceptable cytotoxicity and enhanced antibacterial and antiviral activities compared to free HARF. They showed a higher bactericidal effect against Staphylococcus aureus and Escherichia coli, with a MIC value of $0.025 \mathrm{mg} / \mathrm{mL}$, as compared to free HARF (MIC of 0.50 $\mathrm{mg} / \mathrm{mL}$ ). Moreover, the designed NPs exhibited high selective antiviral activity against the $\mathrm{H} 1 \mathrm{~N} 1$ influenza virus without affecting the host, MDCK cells. Biocompatible nanocarriers loaded with natural extracts with antimicrobial activity could be explored as future effective treatments of infections.

Supplementary Materials: The following are available online at https:/ / www.mdpi.com/article/ 10.3390 / pharmaceutics14010142/s1, Figure S1. (A) Structure of HPßCD with appropriate protons numbered. ${ }^{1} \mathrm{H}$ NMR spectra of (B) HPßCD, (C) HARF, and (D) HARF-HPßCD complex.

\begin{abstract}
Author Contributions: Conceptualization, S.A.F. and H.M.E.-S.A.; methodology, S.A.F. and H.A.M.; data curation, S.A.F. and N.K.M.; software, S.A.F. and H.A.M.; Resources, A.N.E., M.Y.I. and H.M.E.-S.A.; writing-original draft preparation, S.A.F. and H.M.E.-S.A.; writing-review and editing, S.A.F., H.A.M., A.N.E., M.Y.I. and H.M.E.-S.A.; funding acquisition, H.M.E.-S.A.; supervision, H.M.E.-S.A.; project administration, H.M.E.-S.A. All authors have read and agreed to the published version of the manuscript.
\end{abstract}

Funding: This project was funded by a grant from the American University in Cairo to H.M.E.-S.A. Funding number: SSE-CHEM-H.A.-FY2I-FY2 2-RG (2-20)-2020-Fcb-28-21-32-34.

Institutional Review Board Statement: Not applicable.

Informed Consent Statement: Not applicable.

Conflicts of Interest: The authors declare no conflict of interest.

\section{References}

1. Influenza (Seasonal). Available online: https://www.who.int/en/news-room/fact-sheets/detail/influenza-(seasonal) (accessed on 22 November 2021).

2. Mogana, R.; Adhikari, A.; Tzar, M.N.; Ramliza, R.; Wiart, C. Antibacterial activities of the extracts, fractions and isolated compounds from canarium patentinervium miq. Against bacterial clinical isolates. BMC Complement. Med. Ther. 2020, $20,228$. [CrossRef] [PubMed]

3. Fahmy, S.A.; Mamdouh, W. Garlic oil-loaded PLGA nanoparticles with controllable size and shape and enhanced antibacterial activities. J. Appl. Polym. Sci. 2018, 135, 46133. [CrossRef]

4. Omrani, M.; Keshavarz, M.; Nejad Ebrahimi, S.; Mehrabi, M.; McGaw, L.J.; Ali Abdalla, M.; Mehrbod, P. Potential Natural Products Against Respiratory Viruses: A Perspective to Develop Anti-COVID-19 Medicines. Front. Pharmacol. 2021, $11,2115$. [CrossRef]

5. Fahmy, S.A.; Fawzy, I.M.; Saleh, B.M.; Issa, M.Y.; Bakowsky, U.; Azzazy, H.M.E.-S. Green Synthesis of Platinum and Palladium Nanoparticles Using Peganum harmala L. Seed Alkaloids: Biological and Computational Studies. Nanomaterials 2021, $11,965$. [CrossRef] [PubMed]

6. Fahmy, S.A.; Issa, M.Y.; Saleh, B.M.; Meselhy, M.R.; Azzazy, H.M.E.A. Peganum harmala alkaloids self-assembled supramolecular nanocapsules with enhanced antioxidant and cytotoxic activities. ACS Omega 2021, 6, 11954-11963. [CrossRef] 
7. Azzazy, H.M.E.-S.; Fahmy, S.A.; Mahdy, N.K.; Meselhy, M.R.; Bakowsky, U. Chitosan-Coated PLGA Nanoparticles Loaded with Peganum harmala Alkaloids with Promising Antibacterial and Wound Healing Activities. Nanomaterials 2021, 11, 2438. [CrossRef] [PubMed]

8. Pathan Aslam, R.; Vadnere Gautam, P.; Singhai Abhay, K.; Kulkarni Bharti, U. Peganum harmala: A Phyto-pharmacological Review. Inventi Rapid: Planta Activa 2012, 2012, 2-4.

9. Jinous, A.; Ramezanloo, F. Chemistry, pharmacology and medicinal properties of Peganum harmala L. Afr. J. Pharm. Pharmacol. 2012, 6, 1573-1580. [CrossRef]

10. Grosso, G.; Bei, R.; Mistretta, A.; Marventano, S.; Calabrese, G.; Masuelli, L.; Giganti, M.G.; Modesti, A.; Galvano, F.; Gazzolo, D Effects of vitamin C on health: A review of evidence. Front. Biosci. 2013, 18, 1017-1029. [CrossRef]

11. Hemilä, H. Vitamin C and infections. Nutrients 2017, 9, 339. [CrossRef] [PubMed]

12. Fahmy, S.A.; Ponte, F.; Fawzy, I.M.; Sicilia, E.; Bakowsky, U.; Azzazy, H.M.E.-S. Betaine host-guest complexation with a calixarene receptor: Enhanced in vitro anticancer effect. RSC Adv. 2021, 11, 24673-24680. [CrossRef]

13. Fahmy, S.A.; Alawak, M.; Brüßler, J.; Bakowsky, U.; El Sayed, M.M.H. Nanoenabled Bioseparations: Current Developments and Future Prospects. BioMed Res. Int. J. 2019, 2019, 4983291. [CrossRef] [PubMed]

14. Fahmy, S.A.; Ponte, F.; Abd El-Rahman, M.K.; Russo, N.; Sicilia, E.; Shoeib, T. Investigation of the host-guest complexation between 4-sulfocalix[4]arene and nedaplatin for potential use in drug delivery. Spectrochim. Acta-Part A Mol. Biomol. Spectrosc. 2018, 193, 528-536. [CrossRef] [PubMed]

15. Fahmy, S.A.; Ponte, F.; Sicilia, E.; El-Said Azzazy, H.M. Experimental and Computational Investigations of Carboplatin Supramolecular Complexes. ACS Omega 2020, 5, 31456-31466. [CrossRef]

16. Fahmy, S.A.; Ponte, F.; Fawzy, I.M.; Sicilia, E.; Bakowsky, U.; Azzazy, H.M.E.A. Host-Guest Complexation of Oxaliplatin and Para-Sulfonatocalix[n]Arenes for Potential Use in Cancer Therapy. Molecules 2020, 25, 5926. [CrossRef]

17. Fahmy, S.A.; Brüßler, J.; Ponte, F.; Abd El-Rahman, M.K.; Russo, N.; Sicilia, E.; Bakowsky, U.; Shoeib, T. A study on the physicochemical properties and cytotoxic activity of $p$-sulfocalix[4]arene-nedaplatin complex. J. Phys. Conf. Ser. 2019, 1310, 012011. [CrossRef]

18. Fahmy, S.A.; Brüßler, J.; Alawak, M.; El-Sayed, M.M.H.; Bakowsky, U.; Shoeib, T. Chemotherapy based on supramolecular chemistry: A promising strategy in cancer therapy. Pharmaceutics 2019, 11, 292. [CrossRef]

19. Fahmy, S.A.; Ramzy, A.; Saleh, B.M.; Azzazy, H.M.E.-S. Stimuli-Responsive Amphiphilic Pillar[n]arene Nanovesicles for Targeted Delivery of Cancer Drugs. ACS Omega 2021, 6, 25876-25883. [CrossRef]

20. Chen, J.; Qin, X.; Zhong, S.; Chen, S.; Su, W.; Liu, Y. Characterization of curcumin/cyclodextrin polymer inclusion complex and investigation on its antioxidant and antiproliferative activities. Molecules 2018, 23, 1179. [CrossRef]

21. Mohan, L.J.; McDonald, L.; Daly, J.S.; Ramtoola, Z. Optimising PLGA-PEG nanoparticle size and distribution for enhanced drug targeting to the inflamed intestinal barrier. Pharmaceutics 2020, 12, 1114. [CrossRef]

22. Tammam, S.N.; Azzazy, H.M.E.A.; Lamprecht, A. Biodegradable Particulate Carrier Formulation and Tuning for Targeted Drug Delivery. J. Biomed Nanotechnol. 2015, 11, 555-577. [CrossRef]

23. Perinelli, D.R.; Cespi, M.; Bonacucina, G.; Palmieri, G.F. PEGylated polylactide (PLA) and poly (lactic-co-glycolic acid) (PLGA) copolymers for the design of drug delivery systems. J. Pharm. Investig. 2019, 49, 443-458. [CrossRef]

24. Devasvaran, K.; Jairaman, S.; Yahaya, N.A.; Jaganath, I.B.S.; Khung, Y.L.; Lim, V.; Ngalim, S.H. PEG-b-PLGA nanoparticles loaded with Geraniin from Phyllanthus watsonii extract as a phytochemical delivery model. Appl. Sci. 2020, 10, 4891. [CrossRef]

25. Alhakamy, N.A. Development and Evaluation of Icariin-Loaded PLGA-PEG Nanoparticles for Potentiation the Proapoptotic Activity in Pancreatic Cancer Cells. AAPS PharmSciTech 2021, 22, 1-11. [CrossRef] [PubMed]

26. Del Amo, L.; Cano, A.; Ettcheto, M.; Souto, E.B.; Espina, M.; Camins, A.; García, M.L.; Sánchez-López, E. Surface functionalization of plga nanoparticles to increase transport across the bbb for alzheimer's disease. Appl. Sci. 2021, 11, 4305. [CrossRef]

27. Rafiei, P.; Haddadi, A. Docetaxel-loaded PLGA and PLGA-PEG nanoparticles for intravenous application: Pharmacokinetics and biodistribution profile. Int. J. Nanomed. 2017, 12, 935-947. [CrossRef]

28. Plenagl, N.; Duse, L.; Seitz, B.S.; Goergen, N.; Pinnapireddy, S.R.; Jedelska, J.; Brüßler, J.; Bakowsky, U. Photodynamic therapyhypericin tetraether liposome conjugates and their antitumor and antiangiogenic activity. Drug Deliv. 2019, 26, 23-33. [CrossRef]

29. Higuchi, T.; Connors, K.A. Phase Solubility Techniques. Adv. Anal. Chem. Instrum. 1965, 4, 117-212.

30. Liu, L.; Zhao, T.; Cheng, X.; Wang, C.; Wang, Z. Characterization and determination of trace alkaloids in seeds extracts from Peganum harmala linn. Using LC-ESI-MS and HPLC. Acta Chromatogr. 2013, 25, 221-240. [CrossRef]

31. Kurkov, S.V.; Ukhatskaya, E.V.; Loftsson, T. Drug/cyclodextrin: Beyond inclusion complexation. J. Incl. Phenom. Macrocycl. Chem. 2011, 69, 297-301. [CrossRef]

32. Loftsson, T.; Hreinsdóttir, D.; Másson, M. The complexation efficiency. J. Incl. Phenom. Macrocycl. Chem. 2007, 57, 545-552. [CrossRef]

33. Tewes, F.; Munnier, E.; Antoon, B.; Okassa, L.N.; Cohen-Jonathan, S.; Marchais, H.; Douziech-Eyrolles, L.; Soucé, M.; Dubois, P.; Chourpa, I. Comparative study of doxorubicin-loaded poly(lactide-co-glycolide) nanoparticles prepared by single and double emulsion methods. Eur. J. Pharm. Biopharm. 2007, 66, 488-492. [CrossRef]

34. Wang, Y.; Li, P.; Kong, L. Chitosan-modified PLGA nanoparticles with versatile surface for improved drug delivery. AAPS PharmSciTech 2013, 14, 585-592. [CrossRef] [PubMed] 
35. Pinnapireddy, S.R.; Duse, L.; Strehlow, B.; Schäfer, J.; Bakowsky, U. Composite liposome-PEI/nucleic acid lipopolyplexes for safe and efficient gene delivery and gene knockdown. Colloids Surf. B Biointerfaces 2017, 158, 93-101. [CrossRef]

36. Preis, E.; Baghdan, E.; Agel, M.R.; Anders, T.; Pourasghar, M.; Schneider, M.; Bakowsky, U. Spray dried curcumin loaded nanoparticles for antimicrobial photodynamic therapy. Eur. J. Pharm. Biopharm. 2019, 142, 531-539. [CrossRef]

37. Duse, L.; Baghdan, E.; Pinnapireddy, S.R.; Engelhardt, K.H.; Jedelská, J.; Schaefer, J.; Quendt, P.; Bakowsky, U. Preparation and Characterization of Curcumin Loaded Chitosan Nanoparticles for Photodynamic Therapy. Phys. Status Solidi Appl. Mater. Sci. 2018, 215, 1-5. [CrossRef]

38. Chen, M.X.; Li, T.; Peng, S.; Tao, D. Supramolecular nanocapsules from the self-assembly of amphiphilic calixarene as a carrier for paclitaxel. N. J. Chem. 2016, 40, 9923-9929. [CrossRef]

39. El-Shafie, S.; Fahmy, S.A.; Ziko, L.; Elzahed, N.; Shoeib, T.; Kakarougkas, A. Encapsulation of nedaplatin in novel pegylated liposomes increases its cytotoxicity and genotoxicity against a549 and u2os human cancer cells. Pharmaceutics 2020, 12, 863. [CrossRef] [PubMed]

40. Li, B.; Shan, M.; Di, X.; Gong, C.; Zhang, L.; Wang, Y.; Wu, G. A dual pH- and reduction-responsive anticancer drug delivery system based on PEG-SS-poly (amino acid) block copolymer. RSC Adv. 2017, 7, 30242-30249. [CrossRef]

41. Weinstein, M.P.; Patel, J.B.; Burnhman, C.-A.; ZImmer, B.L. M07-Methods for Dilution Antimicrobial Susceptibility Tests for Bacteria That Grow Aerobically, 11th ed.; Approved Standard-2018.

42. Khiralla, A.; Spina, R.; Varbanov, M.; Philippot, S.; Lemiere, P.; Slezack-Deschaumes, S.; André, P.; Mohamed, I.; Yagi, S.M.; Laurain-Mattar, D. Evaluation of antiviral, antibacterial and antiproliferative activities of the endophytic fungus curvularia papendorfii, and isolation of a new polyhydroxyacid. Microorganisms 2020, 8, 1353. [CrossRef]

43. Jang, Y.; Shin, J.S.; Lee, J.Y.; Shin, H.; Kim, S.J.; Kim, M. In vitro and in vivo antiviral activity of nylidrin by targeting the hemagglutinin 2-mediated membrane fusion of influenza A virus. Viruses 2020, 12, 581. [CrossRef]

44. Pauwels, R.; Balzarini, J.; Baba, M.; Snoeck, R.; Schols, D.; Herdewijn, P.; Desmyter, J.; De Clercq, E. Rapid and automated tetrazolium-based colorimetric assay for the detection of anti-HIV compounds. J. Virol. Methods 1988, 20, 309-321. [CrossRef]

45. Gao, S.; Liu, Y.; Jiang, J.; Li, X.; Zhao, L.; Fu, Y.; Ye, F. Encapsulation of thiabendazole in hydroxypropyl- $\beta$-cyclodextrin nanofibers via polymer-free electrospinning and its characterization. Pest Manag. Sci. 2020, 76, 3264-3272. [CrossRef] [PubMed]

46. Veiga, F.J.B.; Fernandes, C.M.; Carvalho, R.A.; Geraldes, C.F.G.C. Molecular modelling and 1H-NMR: Ultimate tools for the investigation of tolbutamide: $\beta$-cyclodextrin and tolbutamide: Hydroxypropyl- $\beta$-cyclodextrin complexes. Chem. Pharm. Bull. 2001, 49, 1251-1256. [CrossRef] [PubMed]

47. Yuan, C.; Jin, Z.; Xu, X. Inclusion complex of astaxanthin with hydroxypropyl- $\beta$-cyclodextrin: UV, FTIR, ${ }^{1} \mathrm{H}$ NMR and molecular modeling studies. Carbohydr. Polym. 2012, 89, 492-496. [CrossRef]

48. Ge, X.; He, J.; Qi, F.; Yang, Y.; Huang, Z.; Lu, R.; Huang, L. Inclusion complexation of chloropropham with $\beta$-cyclodextrin: Preparation, characterization and molecular modeling. Spectrochim. Acta-Part A Mol. Biomol. Spectrosc. 2011, 81, $397-403$. [CrossRef] [PubMed]

49. Meinguet, C.; Masereel, B.; Wouters, J. Preparation and characterization of a new harmine-based antiproliferative compound in complex with cyclodextrin: Increasing solubility while maintaining biological activity. Eur. J. Pharm. Sci. 2015, 77, 135-140. [CrossRef]

50. Imran, M.; Shah, M.R.; Ullah, F.; Ullah, S.; Sadiq, A.; Ali, I.; Ahmed, F.; Nawaz, W. Double-tailed acyl glycoside niosomal nanocarrier for enhanced oral bioavailability of Cefixime. Artif. Cells Nanomed. Biotechnol. 2017, 45, 1440-1451. [CrossRef] [PubMed]

51. Cho, K.; Wang, X.; Nie, S.; Chen, Z.; Shin, D.M. Therapeutic nanoparticles for drug delivery in cancer. Clin. Cancer Res. 2008, 14, 1310-1316. [CrossRef]

52. Li, Y.P.; Pei, Y.Y.; Zhang, X.Y.; Gu, Z.H.; Zhou, Z.H.; Yuan, W.F.; Zhou, J.J.; Zhu, J.H.; Gao, X.J. PEGylated PLGA nanoparticles as protein carriers: Synthesis, preparation and biodistribution in rats. J. Control. Release 2001, 71, 203-211. [CrossRef]

53. Ullah, S.; Shah, M.R.; Shoaib, M.; Imran, M.; Elhissi, A.M.A.; Ahmad, F.; Ali, I.; Shah, S.W.A. Development of a biocompatible creatinine-based niosomal delivery system for enhanced oral bioavailability of clarithromycin. Drug Deliv. 2016, 23, 3480-3491. [CrossRef] [PubMed]

54. Kumari, A.; Yadav, S.K.; Yadav, S.C. Biodegradable polymeric nanoparticles based drug delivery systems. Colloids Surf. B Biointerfaces 2010, 75, 1-18. [CrossRef]

55. Locatelli, E.; Franchini, M.C. Biodegradable PLGA-b-PEG polymeric nanoparticles: Synthesis, properties, and nanomedical applications as drug delivery system. J. Nanoparticle Res. 2012, 14, 1-17. [CrossRef]

56. Zhang, L.; Pornpattananangkul, D.; Hu, C.-M.; Huang, C.-M. Development of Nanoparticles for Antimicrobial Drug Delivery Curr. Med. Chem. 2010, 17, 585-594. [CrossRef]

57. Esmaeili, F.; Hosseini-Nasr, M.; Rad-Malekshahi, M.; Samadi, N.; Atyabi, F.; Dinarvand, R. Preparation and antibacterial activity evaluation of rifampicin-loaded poly lactide-co-glycolide nanoparticles. Nanomed. Nanotechnol. Biol. Med. 2007, 3, 161-167. [CrossRef] [PubMed]

58. Koopaei, M.N.; Maghazei, M.S.; Mostafavi, S.H.; Jamalifar, H.; Samadi, N.; Amini, M.; Malek, S.J.; Darvishi, B.; Atyabi, F.; Dinarvand, R. Enhanced antibacterial activity of roxithromycin loaded pegylated poly lactide-co-glycolide nanoparticles. DARU J. Pharm. Sci. 2012, 20, 1-8. [CrossRef] 
59. Moradi, M.T.; Karimi, A.; Rafieian-Kopaei, M.; Fotouhi, F. In vitro antiviral effects of Peganum harmala seed extract and its total alkaloids against Influenza virus. Microb. Pathog. 2017, 110, 42-49. [CrossRef] [PubMed]

60. Kim, Y.; Kim, H.; Bae, S.; Choi, J.; Lim, S.Y.; Lee, N.; Kong, J.M.; Hwang, Y.; Kang, J.S.; Lee, W.J. Vitamin C is an Essential Factor on the Anti-viral Immune Responses through the Production of Interferon- $\alpha / \beta$ at the Initial Stage of Influenza A Virus (H3N2) Infection. Immune Netw. 2013, 13, 70. [CrossRef]

61. Mahmoud, D.B.; Ismail, W.M.; Moatasim, Y.; Kutkat, O.; ElMeshad, A.N.; Ezzat, S.M.; El Deeb, K.S.; El-Fishawy, A.M.; Gomaa, M.R.; Kandeil, A.; et al. Delineating a potent antiviral activity of Cuphea ignea extract loaded nano-formulation against SARS-CoV-2: In silico and in vitro studies. J. Drug Deliv. Sci. Technol. 2021, 66, 102845. [CrossRef] [PubMed] 